\title{
Lumbar Epidural Injections: Review of Efficacy and Discussion of Practice Options
}

Keywords: Low back pain; Lumbosacral radicular pain; Epidural steroid injection; Transforaminal; Interla minar; Caudal; Lumbar

\begin{abstract}
Background: In the United States, low back pain remains a common problem and a number one reason to see a physician in the outpatient setting. Etiology is complex and likely multifactorial and includes; degenerative disc disease, zygapophysial joint arthritis, vertebral misalignment, muscle strain, ligament sprain, myofascial pain, among others. Based on evidence of increased inflammatory response in disc hemiation and degenerative discs, epidural steroid injections (ESI) have been used to treat lumbosacral radicular pain.

Objective: To focus on the appropriate use of lumbar ESI in treating lumbosacral radic ular pain in the United States, comparing and contrasting transforaminal, interla minar, and caudal approaches for steroid delivery, as well as a comparison of commonly used steroid preparations.
\end{abstract}

Methods: PubMED, MEDUNE, and OVID databases were reviewed utilizing the following subject headings: low back pain, epidural steroid injections, transforaminal epidural steroid injections (TFESI), interla minar epidural steroid injections (ILESI), and caudal epidural steroid injections (CESI) dated from 2000 to 2014. The bibliographies of major articles and reviews were also cross-referenced for additional sources.

Results: A number of articles that included randomized contro trials, comprehensive and systematic reviews, and meta-analyses were found. These provided a broad, detailed overview of the subject, that we used to explore the data surrounding use of ESI for treatment of lumbosacral radicular pain.

Conclusions: Most agree that the evidence for epidural steroid injection efficacy is strongest for short term relief of lumbosacral radicula pain. Most of the systemic reviews have agreed that the strongest evidence for TFESI use is for relief of unilateral lumbosacral radicular pain. The evidence suggests using ILESI in patients with bilateral and/ or multi-level lumbosacral radicular pain. The data correlates efficacy of CESI in low level bilateral or multilevel lumbosacral radicular pa in as well as in patients with history of lumbar surgery.

\section{Introduction}

\section{Epidemiology}

In the United States, low back pain remains common Approximately two-thirds of the population has low back pain at some time in their lives and approximately $26 \%$ of adults surveyed admit to having low back pain within the last three months [1]. Back pain is the fifth most common reason for all physician visits [2] and the second most common symptom-related reason for clinician visits $[3,4]$. The 2010 Global Burden of Disease (GBD) results showed that there is a very high prevalence and burden from low back pain throughout the world [5]. Low back pain was found to have the sixth highest burden of the 291 conditions studied, and caused more disability than any other condition. It is well known that back pain accounts for a large proportion of health care expenditures and that

\section{Journal of}

Orthopedics \& Rheumatology

\section{Christopher T. Plastaras ${ }^{1}$, Ashot S. Kotcharian ${ }^{1 *}$ and Akhil Chhatre ${ }^{2}$}

${ }^{1}$ Department of Physical Medicine and Rehabilitation, University of Pennsylvania Perelman School of Medicine, Philadelphia, USA ${ }^{2}$ Department of Physical Medicine and Rehabilitation and Department of Neurological Surgery, Johns Hopkins University, Baltimore, USA

\section{*Address for Correspondence}

Ashot S. Kotcharian, MD, Department of Physical Medicine and Rehabilitation, University of Pennsylvania Perelman School of Medicine, Philadelphia, USA, Tel: 215-893-2680; E-mail: ashot.kotcharian@uphs.upenn.edu

Submission: 20 February 2015

Accepted: 27 April 2015

Published: 02 May 2015

Copyright: $\odot 2015$ Plastaras CT, et al. This is an open access article distributed under the Creative Commons Attribution License, which permits unrestricted use, distribution, and reproduction in any medium, provided the original work is properly cited.

Reviewed \& Approved by: Dr. Xudong Joshua Li, Assistant Professor, Department of Orthopaedic Surgery, University of Virginia, USA

these expenditures have been increasing substantially [6]. In fact, these expenditures have been increasing more rapidly than overall health expenditures [6]. Taken together with the lost productive time in the workplace, estimated to cause an approximate loss of five hours per week per worker, the over cost is estimated at $\$ 61$ billion per year [7]

The etiology of low back pain remains a complex and likely multifactorial spectrum of degenerative diseases of the spine. Pain generated from problems with the intervertebral discs, zygapophysial joint arthritis, vertebral misalignment, muscles, ligaments, fascia, or neural structures is difficult to determine. While for most, episodes of back pain are self-limited and resolve without specific therapy, for others it is recurrent or chronic and causes significant pain that interferes with employment and quality of life. Treatment varies and may include conservative management, interventional procedures, and surgery.

\section{Conservative management}

Conservative management recommended for low back pain includes rest, medications and therapy. Medications available include NSAIDs, acetaminophen, centrally acting skeletal muscle relaxants, glucocorticoids, anticonvulsants, and opioids. Therapy options may include physical therapy, manipulation, yoga, acupuncture, massage therapy, and modalities.

\section{Interventional procedures}

Currently there are a large variety of therapeutic interventions available to treat low back pain. These include spinal interventions such as Epidural Steroid Injections (ESI), zygapophysial joint intra- 
articular injections, nerve blocks, radiofrequency ablation, and spinal cord neuromodulation [8]. The main objectives of interventional procedures are to improve pain and function so that the patient is able to participate in a comprehensive physical therapy program where any biomechanical deficiencies can be addressed.

\section{Surgical management}

It is critical for the evaluating specialist to be cognizant of the indications for surgical referral. The following are indications for a referral to either a neurosurgeon or orthopaedic spine surgeon: suspected spinal cord compression with myelopathy, intractable pain refractory to medications, cauda equina syndrome, and progressive or severe neurologic deficit [9]. The clinical red flags to be aware of are gait ataxia/upper motor neuron changes (myelopathy), bowel/ bladder dysfunction (cauda equina syndrome), night pain/weight loss (malignancy), and fevers/chills (infection).

The object of this evidence-based review is to focus on the appropriate use of lumbar ESI in treating lumbosacral radicular pain in the United States, comparing and contrasting transforaminal, interlaminar, and caudal approaches for steroid delivery, a look at local anesthetics and a comparison of commonly used steroid preparations.

\section{Lumbar Epidural Steroid Injections}

Injection of corticosteroids into the epidural space has long been used as a treatment for lumbosacral radicular pain due to disc herniation or degeneration. The basis for this treatment stems from evidence that suggests there is an increased production of proinflammatory mediators and cytokines because of disc herniation [1015]. This seems to be also the case in degenerative painful disc where there is the presence of higher levels of interleukin-6, interleukin-8 and prostaglandin E2 $[16,17]$. It is therefore believed that introducing corticosteroid into this space will inhibit the inflammatory cascade and provide pain relief. There is reasonable data to support lumbar epidural steroid use for acute symptoms with short term relief [18]. Young et al. highlighted a few prospective RCTs demonstrating the efficacy of epidural steroid injections up to six months [19]. More recently, Friedly et al. showed that for lumbar stenosis, epidural injection of glucocorticoids with lidocaine offered minimal additional benefit compared to injection of lidocaine alone, although some have questioned the study design and interpretation of its data [20,21]. In the study a lidocaine only group and a glucocorticoid-lidocaine group both showed decreased pain and improved function at 3 weeks and 6 weeks, with a small but significant difference favoring the glucocorticoid-lidociane group at 3 weeks. Also at 6 weeks, the glucocorticoid-lidocaine group reported more improvement in function and higher satisfaction with their treatment. Whether both help and it does not make a difference if glucocorticoid is used or whether the pain improves for other reasons including natural reasons is hard to infer as the trial lacked a sham control group. Nevertheless the short-term relief of pain and improved function, along with physical therapy and medications, give these patients a nonoperative option to treat their pain. This observed short term benefit may be the reason that despite the lack of evidence for efficacy as a long-term efficacy for chronic back pain due to spinal spondylosis and stenosis, the use of ESIs has increased dramatically in recently years, with an estimated 11 million injections performed in the US annually [22].

Three routes may be used to introduce corticosteroid into the lumbosacral epidural space: Transforaminal Epidural Steroid Injections (TFESI), Interlaminar Epidural Steroid Injections (ILESI), and Caudal Epidural Steroid Injections (CESI).

\section{Transforaminal epidural steroid injections}

TFESI is a procedure that is commonly used today as a treatment for lumbosacral radicular pain. The procedure involves delivering a quantity of a corticosteroid preparation into the immediate vicinity of a spinal nerve and its roots. This is done by way of the intervertebral foramen in which the target nerve lies.

Compared to ILESI and CESI, the transforaminal route is a more recently described approach and became a more common practice in the US at the close of the $20^{\text {th }}$ century. This change was prompted by several factors including increasing use of fluoroscopic guidance, reports from systemic reviews that the conventional routes were not as effective as once believed, increasing use of diagnostic selective nerve root injections, and the suggestions that perhaps epidural corticosteroids would be more effective if delivered more accurately to site of pathology, often anterior structures such as the intervertebral disc [23].

The thought that TFESI would be more effective is based on evidence from laboratory experiments that inflammatory process may play a major role in the genesis of symptoms when lumbar nerve roots are affected by disc herniations [10-15,24-28]. It is therefore believed that the advantage of a transforaminal route of administration is that it deposits the medication near the nerve root and in the anterior epidural space at the interface between the herniated disc (or foraminal stenosis) and the inflamed nerve roots.

Another reason for the emergence of TFESI was that there was concern with whether there was actual epidural distribution occurring with ILESI and CESI. Even if an actual epidural distribution was achieved it was still questionable if there was sufficient enough ventral distribution to the anterior epidural region in which herniation may be located [29].

Furthermore, these prior approaches (interlaminar and caudal) typically needed to use excessive drug volume and increased dose, which increased risk of potential systemic adverse effects. Fluoroscopically guided TFESI began to be implemented as one method to achieve a more effective treatment with lower amounts of drug needed to be used. While in theory multilevel and bilateral transforaminal epidural injections may deliver more volume of medication efficiently, there are no studies to validate these techniques. It should be noted that as a result each level performed during a single procedure encounter multiplies the risk associated with the single encounter [30]. Subsequent studies showed some evidence that indeed TFESI did have a superior therapeutic effect compared to ILESI and CESI with less medication needed for efficacy [29,31,32]. A more recent systematic review, however, showed that after 2 weeks there is no statistically significant difference in efficacy between the two approaches [33]. The procedure, indications, complications, and efficacy will be discussed below.

\section{Interlaminar epidural steroid injections}


This injection delivers medication via a loss-of-resistance technique through the posteriorly located ligamentum flavum. ILESI have some advantages in treating axial low back pain. One advantage is that most contrast agent (and thus medication once it is injected) is seen to spread bilaterally in the epidural space. The advantage is that with just a single injection you have not just bilateral distribution of medication but should potentially also cover more lumbar levels and more epidural space; this non-selectivity is sometimes clinically helpful in those individuals with multilevel pathology. Thus, in patients with bilateral distribution of pain or multi-level involvement an ILESI may be more appropriate. A second advantage is that there is less extravasation of contrast agent and therapeutic medication into the spinal nerve spaces compared to the TFESI. A third advantage is that, in the authors experience, ILESI are usually less painful than TFESI. A fourth advantage is that the anatomic location is less likely to canulate radicular arterial structures that might feed spinal cord. Furthermore, ILESI can be placed safely with loss of resistance technique and can be safely placed without contrast in those patients that are contrast allergic; if not contraindicated, the use of contrast confirms definitive epidural placement. Lastly, ILESI can ensure midline medication placement which is often desired in central stenosis and central disc herniations.

The main disadvantage of ILESI is that the injected agent is deposited into the posterior epidural space without a guarantee that it will flow anteriorly where common pain generators such as the disc are located. With addition of fluoroscopy and contrast enhancement it became more evident that ILESI did not achieve ventral epidural contrast spread as effectively as believed. In one study, ventral epidural contrast spread was seen in just $36 \%$ of attempts [34], compared to TFESI where ventral flow as achieved in $100 \%$ of injections [35]. Again, given the evidence of an inflammatory pathophysiology of lumbosacral radicular pain, ILESI are likely at a disadvantage as a treatment option. The procedure, indications, complications, and efficacy will be discussed later in this review.

\section{Caudal epidural steroid injections}

CESI is performed by placing a spinal needle into the sacral epidural space by way of the sacral hiatus. The main advantage of this approach is that it is relatively easy to perform, especially in individuals with a thin body habitus. CESI is commonly preferred in treating patients with lower lumbar and sacral involvement, in postsurgical patients, and in patients with bilateral or multilevel involvement. The main disadvantage is that it requires larger volumes in order to fill the sacral epidural space before the injected medication can reach the lumber region, which dilutes the medication. CESI rarely reach higher than the L5-S1 segmental level [36]. In addition, there seems to be considerably more discomfort during CESI compared to the other routes of ESI administration [37]. The procedure, indications, complications, and efficacy will be discussed below.

\section{Complications of epidural steroid injections}

All epidural steroid injections share risk of major and minor complications. The major complications include infection, bleeding, permanent skin changes, allergic or unexpected drug reaction with minor or major consequences, intravascular injection, air embolism, epidural hematoma, dural puncture, intrathecal injection, nerve injury, paralysis, chemical meningitis, and discitis [29,36]. Minor complications include injection site soreness, new pain, worsening of pain, spinal headache, transient non-spinal headache, transient hypotension, vasovagal syncope, allergic reaction, nausea, and vomiting.

Specifically for vasovagal episodes, Kennedy et al. studied the incidence broken down by variables over 8000 fluoroscopicallyguided injections [38]. The authors found that male sex, age under 65 , and pre-procedure pain less than $5 / 10$ were significantly associated with vasovagal events.

\section{Use of Flouroscopy}

For a long time ESIs were done blindly and until the introduction of fluoroscopically guided ESIs there was no objective way to confirm that the medication was delivered to the targeted area. The evidence for blind ESI has been highly variable and consistently inferior compared to fluoroscopically-guided injections [39]. There are clear disadvantages and risks of performing injections without use of fluoroscopy. Blind ESI have a much higher risk of intravascular placement of the needle, extra-epidural placement of the needle, dural puncture and trauma to spinal cord [42]. The miss rate for blind injections can be as high as $40 \%$ even in experienced hands [40]. Aspiration alone is not sensitive enough to detect intravascular needle placement [41]. Blind injection also require larger volumes which dilutes the injectate, have preferential cranial and posterior flows of the solution, and can be difficult to place especially in postsurgical patients and below the L4-L5 level [39]. These disadvantages and risks may be avoided or reduced with use of contrast with intermittent live fluoroscopy. The risk of intravascular injection can be further reduced by use of digital subtraction angiography, which allows improved visualization of vascular structures $[42,43]$.

\section{Frequency of Injections}

There has been no overall consensus as to the timing and frequency of lumber ESI needed for effective treatment of lumbosacral radicular pain. Although a series of three injections was fairly common practice, a 2008 review found no basis for a series of three, nor could it conclude what an appropriate frequency of injections is due to lack of research [44]. A single well placed fluoroscopically guided injection may be adequate, and an alternative approach may be considered if it is not. Average of one to three injections is needed to achieve significant improvement [36,45-52]. However, given the small but real chances of significant complications, if the first two injections were technically placed correctly with appropriate flow of medication based on contrast flow pattern still afforded no significant pain relief, increased scrutiny should be applied before considering a third injection as the risk-benefit ratio may no longer be favorable. The American Society of Interventional Pain Physicians (ASIPP) guidelines also mention the lack of data for an effective number of injection and recommend frequency should be two months or longer between each injection and no more than four injections per year [53]. The International Spine Intervention Society (ISIS) guidelines recommend no more than four injections in a 6 month period [54].

\section{Corticosteroids}

Some of the most commonly used corticosteroids in ESI 
include dexamethasone, betamethasone, methylprednisolone, and triamcinolone [55-60]. Dexamethasone aside, these are all particulate steroids. In terms of metabolic activity, dexamethasone has a faster onset but shorter duration of action when compared with particulate preparations [61]. Given the short duration of action of dexamethasone, some clinicians view particulate corticosteroids as more appropriate therapeutic choices. Yet there are multiple studies that have shown evidence of no clinically or statistically significant difference in efficacy of particulate and nonparticulate steroids [6265]. In one of these studies, Kennedy et al. compared triamcinolone and dexamethasone, both with statistically significant improvements in pain and function at 2 weeks, 3 months, and 6 months. The dexamethasone group did receive slightly more injections than the triamcinolone group with 1 or 2 injections required for symptomatic relief. This comparison of a nonparticulate vs particulate steroids is the most recent data with very little published on this type of comparison in the past. This paucity of evidence along with the chance of fewer injections required for symptomatic relief might be the reason for continued particulate steroid use.

\section{Safety and risk}

While allergic reaction to steroid is a rare complication [66], the epidural injection of steroids can suppress the secretion of glucocorticoids by the adrenal gland for about two to three weeks $[67,68]$. True steroid side-effects such as a Cushingoid syndrome or hypercorticalism have been recorded, but only following administration of either large or frequent doses of steroid [69-72]. More commonly patients may experience facial flushing, anxiety, sleeplessness, and high blood sugar [73,74].

There is also evidence that suggests that the added exposure to glucocorticoids resulting from ESI may lead to increased bone fragility and therefore ESI should be approached cautiously in patients at risk for osteoporotic fractures [75]. Also rare, but of significant concern, is the inadvertent injection of particulate corticosteroids into a vertebral or foraminal artery which may cause brain and spinal cord embolic infarcts. If intravascular injection were to happen, the steroid particle size could be directly related to the probability that a clinically significant infarct would occur. Houten and Errico reported paraplegia in three patients after lumbosacral nerve root block using either betamethasone or methylprednisolone [76], while Kennedy et al. reported paraplegia in two patients following lumbar TFESI with betamethasone and methylprednisolone respectively [77].

If these cases of paraplegia are due to spinal cord embolic infarcts then it is possible that corticosteroids with particles significantly smaller than red blood cells (average size 6-8 $\mu \mathrm{m}$ ) might be safer. Derby et al. studied and documented particulate size in commonly used corticosteroid preparations using light microscopy [56]. The largest measured dexamethasone particles were much smaller than median sized red blood cells (5-10 times smaller), while the smallest were too small to be measured. There was no aggregation observed. The size of triamcinolone particles varied, with the largest particles found to be more than 12 times greater than median-sized red blood cells, and extensive aggregation was observed. Betamethasone particles, although small in size, were densely packed and there was extensive aggregation, with some large aggregates being more than 12 times greater than the size of red blood cells. As for methylprednisolone, the particles were uniform and smaller than red blood cells. They were densely packed, yet few aggregations were observed, and most particles and aggregations were smaller than red blood cells [78].

Benzon et al. also compared particulate and nonparticulate steroids for size and found similar results. They studied dexamethasone, betamethasone, triamcinolone, and methylprednisolone [60]. Dexamethasone and betamethasone solutions were both described as pure liquid with no identifiable particles, while a methylprednisolone and triamcinolone were opaque and amorphous in appearance. They measured and found that commercial betamethasone had no particles larger than $500 \mu \mathrm{m}$, while $3 \%$ of particles in triamcinolone were found to be larger than $500 \mu \mathrm{m}$ and $1 \%$ measured to be larger than $1000 \mu \mathrm{m}$.

A no particulate steroid such as dexamethasone is likely safer and in theory should not result in embolic infarction of the spinal cord. Yet being a soluble steroid it is more rapidly cleared from the spinal canal, resulting in a shorter duration of effect, and thus theoretically less effective than a particulate steroid. Park et al. conducted a randomized, controlled trial comparing effectiveness of no particulate steroid (dexamethasone) with particulate steroid (triamcinolone) in treating lumbar back and lumbar radicular pain [59]. In this study, 106 patients were randomized into equal groups of 53 and the primary outcomes were improvement in pain on the VAS as well as improvements on McGill Pain Questionnaire and Revised Oswestry Low Back Pain Disability Index. The results showed that while after one month both groups had significant improvements in outcomes, the patients who were injected with triamcinolone had significantly lower VAS pain scores. The results on the McGill and Oswestry questionnaires were not significantly different.

Another randomized study of corticosteroids compared the efficacy and side-effects of dexamethasone to methylprednisolone [58]. Their results showed a slight trend toward dexamethasone being slightly less effective and of shorter duration than methylprednisolone but this were not found to be statistically significant.

A 2011 prospective randomized, double-blind study by Ahadian et al. investigated the efficacy dose-response profile, and safety of 3 doses of dexamethasone ( $4 \mathrm{mg}, 8 \mathrm{mg}, 12 \mathrm{mg}$ ) in a total of 98 subjects [55]. Their results showed a statistically significant improvement in radicular pain at 12 weeks. Their results also showed no difference in efficacy among the 3 different doses. This is significant as it means a lower dose can be delivered to achieve the same effect while reducing the risk and side effects of the medication.

The authors of a retrospective observational study assessed the non-inferiority of dexamethasone compared to particulate steroids [57]. They retrospectively assessed the results of using dexamethasone $(10 \mathrm{mg})$ compared to triamcinolone $(80 \mathrm{mg})$ and betamethasone (12 $\mathrm{mg}$ ) in TFESI to treat patients with radicular pain. In looking at pain relief and functional recovery at 2 months post injection they report that the results demonstrated no evidence that dexamethasone is less effective than particulate steroids.

\section{Local Anesthetics}

Local anesthetics work by interrupting neural conduction via inhibiting the influx of sodium ions through channels within neuronal membranes [79-81]. In general, smaller fibers (autonomic, 
small unmyelinated C fibers, and small myelinated fibers) are more susceptible to local anesthetics [80]. They differ in their potency as well as onset and duration of anesthesia on account of their molecular structures. The three components that make up the molecular structure of all local anesthetics are: 1) tertiary amine, 2) intermediate ester or amide linkage, and 3) a lipophilic aromatic ring. The lipophilic aromatic ring and its substitutes as well as the tertiary state of the amine result in differences in lipid solubility which determines anesthetic potencies of various local anesthetics as well as their time for onset [81]. The differences in local anesthetic duration of action has to do with their affinity for plasma proteins and also on how long a local anesthetic remains in close proximity to neural fibers.

Based on these properties, local anesthetics are most often used to provide temporary anesthesia. However, epidural administration of local anesthetics has sometimes ameliorated pain for periods of time that outlasts $\mathrm{Na}$-channel blockade [80], although the underlying mechanism of this prolonged effect is still largely unknown. Epidural injection of steroids is what has been recommended to be effective in disc herniations and radiculitis given their anti-inflammatory properties. However there is evidence, particularly in cases of lumbar spinal stenosis, that local anesthetics either alone or in combination with steroids are just as effective as steroids [20,80,82-85]; although, steroids seem to be superior initially [84]. In addition some data suggests that local anesthetics have anti-inflammatory properties [86].

\section{Transforaminal Epidural Steroid Injections}

\section{Indications and contraindications}

Based on the latest guidelines $[53,87]$, the indication for TFESI is lumbosacral radicular pain in patients: who require relief of their pain and who have not improved with non-operative treatments, whose pain is likely to have an inflammatory basis, and for whom non-operative interventions are not indicated.

The following are considered to be absolute contraindications to TFESI: evidence of an untreated localized infection in the field of the procedure, known anaphylactic reaction to contrast medium, a patient who is unable to cooperate during the procedure, a patient who is unable or unwilling to consent to the procedure. Relative contraindications include: allergy to any of the drugs that are to be administered, pregnancy, concurrent use of anticoagulants, anatomical derangements that compromise the safe and successful conduct of the procedure, known systemic infection, coexisting disease producing significant respiratory or cardiovascular compromise, and immunosuppression.

\section{Procedure}

The patient is positioned prone. The skin is then prepped in sterile manner. The fluoroscope is positioned to provide an oblique view. The injection then begins by anesthetizing the skin and soft tissues with a local anesthetic (e.g. $2 \mathrm{~mL}$ of $1 \%$ lidocaine). Using fluoroscopic guidance, a sterile spinal needle (e.g. 22 gauge, 3.5 or 5 inch) is then positioned at the foramen in the superior aspect above the exiting spinal nerve. Precise needle placement is then confirmed by fluoroscopy. Contrast dye (e.g. Omnipaque 300) is then injected through microbore tubing under live fluoroscopy. Ideally medial and superior epidural flow pattern are observed. Once there is no evidence observed of intravascular uptake or intrathecal flow the injectate solution is then administered (e.g. $2 \mathrm{~mL}$ of $1 \%$ lidocaine as a test dose followed by $1.6 \mathrm{~mL}$ of dexamethasone solution $(10 \mathrm{mg} / \mathrm{mL})$ ).

\section{Complications}

As with other epidural injections, complications include vasovagal response, injection site soreness, new pain, worsening of pain, infection, bleeding, permanent skin changes, allergic or unexpected drug reaction with minor or major consequences, nerve injury, paralysis, dural puncture, and headache. A complication more specific for TFESI has to do with the radicular artery and the fact that it travels within the foramen where the nerve root is targeted in this intervention. If the radicular artery is penetrated by needle tip and there is administration of steroid preparation into the artery, the steroid preparation may act as an embolus. This may result in ischemia of the spinal cord if the artery happens to be a reinforcing artery, especially if the artery of Adamkiewicz is penetrated, which is most commonly found on the left side and between T9 and L3 [88]. Although extremely rare, there are known cases of paraplegia after TFESI $[76,77]$. It is therefore crucial that following transforaminal access, injected contrast medium shows no intra-arterial injection. Other major complications include air embolism, dural sac puncture, intrathecal injection, nerve injury, and discitis [29].

In 2000, Botwin et al. wrote that that they observed no major complications and a minor complications rate of $9.6 \%$ in TFESI [89]. Huston et al. prospective study of 151 patients did not have any major complications, and their side effects were as follows: increased pain at the injection site $(17.1 \%)$, increased radicular pain (8.8\%), lightheadedness (6.5\%), increased spine pain (5.1\%), nausea (3.7\%), nonspecific headache (1.4\%), and vomiting (0.5\%). In a retrospective study published in 2006, Stalcup et al. also reported no major complication and an incidence rate of $5.5 \%$ for overall minor complications in TFESI $[90,91]$. In a prospective study published in 2011, Karaman et al. evaluated the complications of 1305 implementations of lumbar TFESI in 562 patients in the period of more than 5 years [29]. They reported no major complications and a minor complications rate of $11.5 \%$. They found that the most frequent minor complication was vasovagal reaction (8.7\%). Other studies corroborated that the most frequent adverse event was vasovagal response [73].

\section{Efficacy}

A systematic review by Boswel et al. published in 2003 analyzed randomized and nonrandomized clinical trials of patients with low back pain with and without leg pain of at least 3 month duration treated with ESI for primary outcome of pain [92]. Using 5 levels of evidence criteria for effectiveness (conclusive, strong, moderate, limited and indeterminate) they found strong evidence for shortterm and long-term relief in managing lumbosacral radicular pain, and inconclusive evidence of effectiveness in post lumbar surgery syndromes.

A systematic review by Abdi et al. published in 2005 evaluated interlaminar, transforaminal, and caudal epidural injections for managing chronic ( $>3$ mo duration) axial and radicular pain and found that the evidence for TFESI in managing radicular pain was strong for short-term relief and moderate for long-term relief [93]. 
Their review also found that the evidence for managing axial pain with TFESI was indeterminate, and for spinal stenosis as well as post lumbar surgery back pain were limited. Two years later another systematic review by Abdi et al. found same results [94]

In a systematic review by Buenaventura et al. in 2009, 4 randomized trials evaluating lumbar TFESI were included [95]. They found that for short-term relief, all 4 studies showed positive results. As for long term relief, two studies had positive results, one study had negative results, and the fourth study results were not available. They evaluated the level of evidence of these trials and have determined that the indicated evidence for lumbar TFESI is Level II-1 for shortterm relief and Level II-2 for long-term relief in managing chronic low back and radicular pain based on the US Preventative Services Task Force (USPSTF) criteria.

A prospective randomized study by Ghahreman et al. showed that transforaminal injection of steroid with local anesthetic was superior to transforaminal injection of anesthetic alone, normal saline, intramuscular steroid, or intramuscular saline. The same study also found that over time the number of patients who maintained relief diminished [96]. There is also evidence that TFESI are more often successful in patients who do not have significant compression of the nerve root and thus are more likely to have an inflammatory basis for radicular pain [97].

In a 2011 literature review by Rho et al. using evidence criteria by Wright [98], they found that evidence supporting use of TFESI was strongest for patients who have acute to sub-acute unilateral radicular pain caused by lumbar disc herniation or lumbar spinal stenosis [99]. They also found that there was insufficient evidence to support use of TFESI for axial low back, and no evidence for chronic failed back surgery syndrome.

A 2012 systematic review by Manchikanti et al. evaluated the effect of therapeutic TFESI in managing low back pain and lower extremity pain [100]. They searched relevant literature from 1966 to 2011 and included 27 studies in their analysis with primary outcome measure of short term (up to 6 months) and long term ( $>6$ months) pain relief. They found the evidence for efficacy of TFESI was good for lumbar disc herniations, fair for spinal stenosis, and poor for axial low back pain as well as post lumbar surgery syndrome. Their classification for level of evidence was based on USPSTF criteria.

In 2013, members of the ISIS Standards Committee performed a comprehensive review of the literature with systematic analysis of all published data to determine the effectiveness of lumbar TFESI in the treatment of radicular pain [101]. They reported that while TFESI is not universally effective in treating radicular pain in setting of disc herniation, there is sufficient evidence showing that a substantial proportion of patients with radicular pain do benefit from these injections and that the improvement is not a placebo effect. Their review cited outcome studies that show up to $70 \%$ of patients achieving at least $50 \%$ relief of pain at 1-2 months after treatment and about $30 \%$ achieving complete relief. They also argue that TFESI is not a placebo and statistically is more often effective than transforaminal normal saline, intramuscular normal saline or intramuscular steroids.

A 2013 randomized prospective study of 64 patients showed that both ILESI and TFESI were effective in treating chronic radicular pain based on PD-Q scores [49]. The results showed a faster drop in pain after TFESI compared to ILESI. Recent results by van Helvoirt et al. indicate that a course of TFESIs followed by physical therapy (mechanical diagnosis and treatment) may help a substantial proportion of candidates avoid surgical intervention [102]. Another more recent prospective study of 31 patients compared TFESI to CESI and found TFESI to be superior at 6 month follow up [103].

\section{Interlaminal Epidural Steroid Injections}

\section{Indications and contraindications}

Indications for ILESI are similar to the ones discussed above for TFESI and include disc herniation, spinal stenosis, and radiculopathy. ILESI are particularly indicated for spinal stenosis and in cases of bilateral and/or multi-level radiculopathy. For example, ILESI can be considered in a patient who has central canal stenosis with diffuse bilateral symptoms of neurogenic claudication, especially at higher lumbar levels not reachable with CESI. ILESI can also be considered in patients with radiculopathy where TFESI approach would be limiting and difficult such as in patients with severe multilevel foraminal stenosis.

Contraindications are the same as discussed above for TFESI. ILESI should be avoided in patients with a history of posterior spinal surgery or severe central stenosis that obliterates the posterior epidural space, due to increased risk of intrathecal penetration [36].

\section{Procedure}

The patient is positioned prone. The skin is then prepped in sterile manner. The fluoroscope is positioned to provide an anteriorposterior view to expose interlaminar space. The interlaminar epidural injection then begins by anesthetizing the skin and soft tissues with a local anesthetic (e.g. $2 \mathrm{~mL}$ of $1 \%$ lidocaine). Using fluoroscopic guidance, a sterile spinal needle (e.g. 18 gauge 3.5 inch Touhy needle) is then positioned at the interlaminar space using loss of resistance syringe with saline technique. Precise needle placement is confirmed by fluoroscopy. Thencontrast dye (e.g. Omnipaque 300) is injected through microbore tubing under live fluoroscopy. Ideally a superior epidural flow pattern is observed. Once there is no evidence observed of intravascular uptake or intrathecal flow the injectate solution is then administered (e.g. $2 \mathrm{~mL}$ of $1 \%$ lidocaineas a test dose without adverse effect followed by 1-2 mL of corticosteroid such as DepoMedrol (40 $\mathrm{mg} / \mathrm{ml})$, betamethasone $(6 \mathrm{mg} / \mathrm{mL})$ or dexamethasone $(10 \mathrm{mg} / \mathrm{mL})$.

\section{Complications}

As with other epidural injections, complications include vasovagal response, injection site soreness, new pain, worsening of pain, infection, bleeding, permanent skin changes, allergic or unexpected drug reaction with minor or major consequences, nerve injury, paralysis, dural puncture, and headache. The risk of dural sac puncture is higher in ILESI compared to TFESI and CESI [31,36]. Another complication that patients who receive ILESI are at risk for is trauma to the spinal cord [104-106]. It has been reported that in 2.5\% of patients who underwent lumbar epidural steroid injections there was hypotension due to sympathetic efferent blockade [107,108]. An interesting known complication is worsening of pain, a mysterious side effect that may have to do with injection of large volumes of fluid 
into epidural space and may be avoided by injecting slowly $[109,110]$ Although relatively more commonly reported in TFESI, there is one case report of radicular artery injection and paralysis with ILESI [111].

\section{Efficacy}

The literature on the efficacy of fluoroscopically guided lumbar ILESI is not as abundant as on blind injections and overall is rather lacking for both. As far as blind ILESI, multiple control trials have shown that they are no more effective than sham injections [112] In a single-blinded investigation of 39 patients with low back and radicular pain Helliwel et al. treated 20 subjects with ILESI of 80 $\mathrm{mg}$ of methylprednisolone in $10 \mathrm{ml}$ normal saline and compared those patients to 19 control patients who underwent an interspinous injection of $5 \mathrm{ml}$ normal saline [113]. The patients who received an ILESI reported statistically significant reduction in pain levels at 1 and 3 months compared to the control patients. The 2003 systematic review by Boswell et al. concluded that the evidence of ILESI effectiveness is moderate for short-term relief and limited for longterm relief in managing lumbar radicular pain [92].

The systematic reviews by Abdi et al. in 2005 and 2007 found strong evidence for short-term relief of lumbar radicular pain with ILESI, while the evidence for long-term relief was limited [93,94]. They found that the evidence for managing axial low back pain and spinal stenosis pain with ILESI was inconclusive for both. In a systemic review published in 2012, Benyamin et al. analyzed 15 randomized and 11 non-randomized studies, and concluded that the evidence supporting ILESI was good for radicular pain secondary to disc herniation and fair for axial pain without disc herniation [39].

There were two studies in 2010 that compared fluoroscopically guided interlaminar epidural injections of steroid and local anesthetic versus local anesthetic alone[114,115]. Each study evenly divided 70 patients into two groups to receive either local anesthetic alone or local anesthetic and steroid. Comparing success rates (at least 50\% improvement in pain and disability scores), post injection opioid use, and post injection employment status, there was no significant difference seen between two treatments in both studies.

The results from an observational study that was published in 2010 were that ILESI was effective in four-fifths of patients treated for axial low back pain, recurrence was observed in 54\% of those patients, with an approximate symptom free interval of 5 months [116]. There is also some evidence that parasagittal interlaminar approach of epidural steroid injection is more effective for pain relief and improvement in disability than midline interlaminar approach for 6 months in management of low back pain with radicular pain [117]. Finally, as mentioned earlier, the 2014 study by Manchikanti also found the interlaminar approach to be effective, either with steroid or anesthetic alone as the injectate [87].

In regards to superior efficacy of an interlaminar approach versus a transforaminal approach of medication delivery, there remains a paucity of clear evidence favoring one technique versus the other. There have been many attempts to validate each technique as better approach in terms of long term efficacy, however a clear and data driven conclusion is yet to be had $[118,119]$. In some studies, when compared to TFESI, the ILESI provided less pain relief and needed greater number of injections $[120,121]$. There is at least one study that did not find a significant difference in outcomes when comparing fluoroscopically-guided TFESI with ILESI, however in this study all subjects were limited to a single injection [122].

\section{Caudal Epidural Steroid Injections}

\section{Indications and contraindications}

CESI is commonly preferred in treating patients with lower lumbar and sacral involvement, in postsurgical patients, and in patients with bilateral or multilevel involvement [123]. CESI are best used at L4-L5 or L5-S1 levels since the needle is directed to the sacral hiatus, and the injectate is unlikely to reach above the L4-L5 level. It is therefore not recommended to treat more cephalad pathology with CESI. The reason that CESI are preferred in postsurgical patients is due to concern of epidural scarring and if another approach such as ILESI is used there is a higher risk of dural puncture [36].

\section{Procedure}

The patient is positioned prone. The skin is then prepped in sterile manner. The fluoroscope is then positioned to provide a lateral view of the inferior sacrum. The caudal epidural injection then begins by anesthetizing the skin and soft tissues with local anesthetic (e.g. $2 \mathrm{~mL}$ of $1 \%$ lidocaine). Using fluoroscopic guidance, a sterile spinal needle (e.g. 22 gauge 3.5 inch) is then positioned at the sacral hiatus with needle tip below the S2 level. Precise needle placement is confirmed by fluoroscopy. Next, contrast dye (e.g. Omnipaque 300) is injected through microbore tubing under live fluoroscopy. Ideally, a superior epidural flow pattern is observed. Once there is no evidence observed of intravascular uptake or intrathecal flow the injectate solution is then administered (e.g. corticosteroid, lidocaine, and saline).

\section{Complications}

As with TFESI and ILESE, CESI complications include vasovagal response, injection site soreness, new pain, worsening of pain, infection, bleeding, permanent skin changes, allergic or unexpected drug reaction with minor or major consequences, nerve injury, paralysis, dural puncture, and headache. In 139 patients who received 257 fluoroscopically guided CESI, Botwin et al. reported an incidence of $15.6 \%$ of minor complications per injection [124,125]. These complications included vasovagal reaction $(0.8 \%)$, nausea $(0.8 \%)$, facial flushing (2.3\%), increased back pain (3.1\%), transient nonpositional headaches $(3.5 \%)$, and insomnia the night of injection (4.7\%).

\section{Efficacy}

There is evidence that CESI are effective for management of chronic low back pain of discogenic origin. Mathews et al. randomized 57 patients who had chronic low back and radicular pain to get either CESI or local injection of lidocaine over the sacral hiatus [126]. Each group received three injections, and at 1 month $67 \%$ of CESI patient and $56 \%$ of control patients had effective reduction of painful symptoms. At one year follow up the improvement remained greater in the CESI group. The systematic review by Boswel et al. of randomized and nonrandomized trials found that the overall evidence of CESI was strong for short-term relief and moderate for long-term 
relief [92]. They also found that the evidence for chronic low back pain and spinal stenosis was limited due to lack of randomized or double-blind trials evaluating this effect. The systematic reviews by Abdi et al. in 2005 and 2007 found that the evidence for managing chronic lumbar radiculopathy pain with caudal ESI was strong for short-term relief and moderate for long-term relief [93,94]. They found similar level of evidence for managing post-lumbar surgery pain as well. They found the evidence for managing axial low back pain with CESI was moderate.

In a randomized, double-blind, active-control trial by Manchikanti et al. published in 2011, 120 chronic low back pain patients were randomly assigned into two groups [127]. One group received caudal epidural injection of local anesthetic, while a second group received injection of local anesthetic and steroid. Both groups were followed for 12 months. At the end of 12 months both groups saw significant improvement with more improvement seen in Group II participants. In Group II, $72 \%$ of participants showed significant pain relief and $72 \%$ showed significant improvement in functional assessment. In Group I, $63 \%$ of participants showed significant pain relief and 55\% showed significant improvement in functional assessment. This study was limited by not having a placebo group.

A blinded randomized control trial by Iversen et al. published in 2011 found CESI to not be effective in treating chronic (>12 weeks) lumbar radicular pain with their results showing no statistical or clinical difference between sham groups and groups who received CESI [128]. Their study was slightly underpowered.

A 2012 systematic review by Manchikanti et al. reviewed 11 randomized and 5 nonrandomized studies of low back pain with and without radicular pain treated with CESI [129]. Using USPSTF criteria they concluded that the evidence for short and long term relief of chronic pain secondary to disc herniation or radiculitis with CESI was good. For treating chronic axial or discogenic pain, spinal stenosis, and post-lumbar surgery pain, the evidence was fair.

\section{Conclusion}

In the United States, lumbosacral radicular pain remains a common ailment. Although it naturally resolves for majority of patients; this complex and likely multifactorial problem remains difficult to treat for some. The purpose of this paper was to discuss the appropriate use of ESI as a treatment for lumbosacral radicular pain in the US based on present knowledge of their indications, safety, and efficacy. Based on evidence of increased inflammatory response in disc herniation and degenerative discs, epidural injections of corticosteroids have been used to treat lumbosacral radicular pain. TFESI began to be favored as it introduced steroids nearest to the nerve root, had better epidural and ventral distribution, and required less drug volume and dose compared to ILESI and CESI. ILESI and CESI on the other hand do have the advantage of bilateral as well as multi-level distribution and could be of greater benefit for patients with diffuse, bilateral, or multi-level involvement. CESI have additional advantages of being easier to perform, not necessarily requiring use of fluoroscopy, and potentially better for post-surgical patients with extensive scarring where ILESI or TFESI would prove more difficulty and less effective.

Concerning safety, ESIs are generally well tolerated, all sharing similar major and minor complications, and most complications are related to technical problems during the procedure or reaction to steroid. The most worrisome complications are the few reported cases of paraplegia post TFESI and one case after ILESI. However these cases are extremely rare, and with proper technique and fluoroscopic guidance can be avoided. Today fluoroscopically-guided injections are becoming more common, due to concern for major complications and evidence that blind injections have been highly variable and consistently inferior. There is still no consensus as to frequency and timing of ESI except that most patients will require more than one injection. The most commonly used corticosteroids include dexamethasone, betamethasone, methylprednisolone, and triamcinolone, with dexamethasone the only nonparticulate steroid. A nonparticulate steroid such as dexamethasone is likely safer and theoretically should not result in embolic infarction of the spinal cord. Yet being a soluble steroid it is more rapidly cleared from the spinal canal, resulting in a shorter duration of effect, and thus theoretically less effective than a particulate steroid. There is evidence that both confirms and refutes this concern [57,61-63,77].

Most of the systemic reviews have agreed that the strongest evidence for TFESI use is for short-term relief of lumbosacral radicular pain [49,92-95,99-101]. There are many examples in medicine where such short term treatments are justified, such as in treating acute infectious COPD exacerbations with oral corticosteroids and antibiotics or using diuretics for acute CHF overload, neither of which will prevent next exacerbation or provide any long term benefit, but in both cases appropriate and is current standard of care. The evidence for long-term relief with TFESI is at best moderate, and is indeterminate to limiting for axial low back pain, spinal stenosis, and post lumbar surgery syndromes. Most recommend the use of TFESI in patients with unilateral radicular pain. The evidence for efficacy of ILESI in treating lumbosacral radicular pain is moderate to strong for short term, limited for long-term relief, and fair for axial low back pain $[39,92]$. The evidence suggests using ILESI in patients with bilateral and/or multi-level lumbosacral radicular pain. As far as CESI, the evidence appears moderate to strong for both short term and long term pain relief in patients with lumbosacral radicular pain $[92,126,129]$, fair to moderate for axial low back pain, spinal stenosis, and post lumbar surgery syndromes $[93,94,129]$. The data correlates efficacy of CESI in low level bilateral or multilevel radicular pain as well as in patients with history of lumbar surgery.

In summary it is clear that while the evidence has varied and is lacking for long term efficacy, there is sufficient evidence for short term benefit that has made ESI an appropriate option for short term relief of lumbosacral radicular pain. Evidence for ESI used for long term efficacy or prevention of recurrence of lumbosacral radicular pain is lacking. The main objective to justify short term relief of symptoms would be to improve pain and function so that the patient is able to participate in a comprehensive physical therapy program where any biomechanical deficiencies can be addressed. This gives an important window of opportunity to make gains in conservative treatment of lumbosacral radicular pain without the need for surgical care.

\section{References}

1. Deyo RA, Mirza SK, Martin BI (2006) Back pain prevalence and visit rates: estimates from U.S. national surveys, 2002. Spine (Phila Pa 1976) 31: 2724 
Citation: Plastaras CT, Kotcharian AS, Chhatre A. Lumbar Epidural Injections: Review of Efficacy and Discussion of Practice Options. J Orthopedics Rheumatol. 2015;2(1): 12.

ISSN: 2334-2846

2727.

2. Hart LG, Deyo RA, Cherkin DC (1995) Physician office visits for low back pain. Frequency, clinical evaluation, and treatment patterns from a U.S. national survey. Spine (Phila Pa 1976) 20: 11-19.

3. Deyo RA, Tsui-Wu YJ (1987) Descriptive epidemiology of low-back pain and its related medical care in the United States. Spine (Phila Pa 1976) 12: 264 268.

4. Cassidy JD, Carroll LJ, Côté P (1998) The Saskatchewan health and back pain survey: the prevalence of low back pain and related disability in saskatchewan adults. Spine (Phila Pa 1976) 23: 1860-1866.

5. Hoy D, March L, Brooks P, Blyth F, Woolf A, et al. (2014) The global burden of low back pain: estimates from the Global Burden of Disease 2010 study. Ann Rheum Dis 73: 968-974.

6. Martin BI, Deyo RA, Mirza SK, Turner JA, Comstock BA, et al. (2008) Expenditures and health status among adults with back and neck problems. JAMA 299: 656-664.

7. Stewart WF, Ricci JA, Chee E, Morganstein D, Lipton R (2003) Los productive time and cost due to common pain conditions in the US workforce. JAMA 290: 2443-2454.

8. Grewal H, Grewal BS, Patel R (2012) Nonsurgical interventions for low back pain. Prim Care 39: 517-523.

9. Wipf JE, Deyo RA (1995) Low back pain. Med Clin North Am 79: 231-246.

10. Saal JS, Franson RC, Dobrow R, Saal JA, White AH, et al. (1990) High levels of inflammatory phospholipase A2 activity in lumbar disc herniations. Spine (Phila Pa 1976) 15: 674-678.

11. Kang JD, Georgescu HI, McIntyre-Larkin L, Stefanovic-Racic M, Donaldson WF 3rd, et al. (1996) Herniated lumbar intervertebral discs spontaneously produce matrix metalloproteinases, nitric oxide, interleukin- 6, and prostaglandin E2. Spine (Phila Pa 1976) 21: 271-277.

12. Kang JD, Stefanovic-Racic M, Mclntyre LA, Georgescu HI, Evans CH (1997) Toward a biochemical understanding of human intervertebral disc degeneration and herniation. Contributions of nitric oxide, interleukins, prostaglandin E2, and matrix metalloproteinases. Spine (Phila Pa 1976) 22: 1065-1073.

13. Takahashi H, Suguro T, Okazima Y, Motegi M, Okada Y, et al. (1996) Inflammatory cytokines in the herniated disc of the lumbar spine. Spine (Phila Pa 1976) 21: 218-224.

14. Nygaard OP, Mellgren SI, Osterud B (1997) The inflammatory properties of contained and noncontained lumbar disc herniation. Spine (Phila Pa 1976) 22: $2484-2488$

15. O’Donnell JL, O'Donnell AL (1996) Prostaglandin E2 content in herniated lumbar disc disease. Spine (Phila Pa 1976) 21: 1653-1656.

16. Burke JG, Watson RW, McCormack D, Dowling FE, Walsh MG, et al (2002) Intervertebral discs which cause low back pain secrete high levels of proinflammatory mediators. J Bone Joint Surg Br 84: 196-201.

17. Weiler C, Nerlich AG, Bachmeier BE, Boos N (2005) Expression and distribution of tumor necrosis factor alpha in human lumbar intervertebral discs: a study in surgical specimen and autopsy controls. Spine (Phila $\mathrm{Pa}$ 1976) 30: 44-53.

18. Chou R, Atlas SJ, Stanos SP, Rosenquist RW (2009) Nonsurgical interventional therapies for low back pain a review of the evidence for an American Pain Society clinical practice guideline. Spine (Phila Pa 1976) 34: 1078-1093.

19. Young IA, Hyman GS, Packia-Raj LN, Cole AJ (2007) The use of lumbar epidural/transforaminal steroids for managing spinal disease. J Am Acad Orthop Surg 15: 228-338

20. Friedly JL, Comstock BA, Turner JA, Heagerty PJ, Deyo RA, et al. (2014) A randomized trial of epidural glucocorticoid injections for spinal stenosis. $\mathrm{N}$ Engl J Med 371: 11-21.
21. Manchikanti L, Candido KD, Kaye AD, Boswell MV, Benyamin RM, et al. (2014) Randomized trial of epidural injections for spinal stenosis published in the New England Journal of Medicine: further confusion without clarification. Pain Physician 17: E475-E488.

22. Anderson GB (2014) Epidural glucocorticoid injections in patients with lumbar spinal stenosis. N Engl J Med 371: 75-76.

23. Bogduk N (2013) Lumbar transforaminal acess, in international spine intervention society. Practice Guidelines for Spinal Diagnostic and Treatment Procedures, p: 513

24. Elves MW, Bucknill T, Sullivan MF (1975) In vitro inhibition of leucocyte migration in patients with intervertebral disc lesions. Orthop Clin North Am 6: 59-65.

25. Gertzbein SD, Tait JH, Devlin SR (1977) The stimulation of lymphocytes by nucleus pulposus in patients with degenerative disc disease of the lumbar spine. Clin Orthop Relat Res 123: 149-154

26. Mc Carron RF, Wimpee MW, Hudkins PG, Laros GS (1987) The inflammatory effect of nucleus pulposus: a possible element in the pathogenesis of lowback pain. Spine (Phila Pa 1976) 12: 760-764.

27. Olmarker K, Blomquist J, Strömberg J, Nannmark U, Thomsen P, et al. (1995) Inflammatogenic properties of nucleus pulposus. Spine (Phila Pa 1976) 20: 665-669.

28. Cavanaugh JM, Ozaktay AC, Vaidyanathan S, Orthopaedic Research Society (1994) Mechano- and chemosensitivity of lumbar dorsal roots and dorsal root ganglia: An in vitro study. Transactions of the Annual Meeting- Orthopaedic Research Society 109.

29. Karaman H, Kavak GO, Tüfek A, Yldrm ZB (2011) The complications of transforaminal lumbar epidural steroid injections. Spine (Phila Pa 1976) 36: E819-E824.

30. Lee JH, An JH, Lee SH (2009) Comparison of the effectiveness of interlaminar and bilateral transforaminal epidural steroid injections in treatment of patients with lumbosacral disc herniation and spinal stenosis. Clin J Pain 25: 206-210.

31. Manchikanti L (2000) Transforaminal Lumbar Epidural Steroid Injections Pain Physician 3: 374-398.

32. Cluff R, Mehio AK, Cohen SP, Chang Y, Sang CN, et al. (2002) The technical aspects of epidural steroid injections: a national survey. Anesth Analg 95: 403-408.

33. Chang-Chien GC, Knezevic NN, McCormick Z, Chu SK, Trescot AM, et al. (2014) Transforaminal versus interlaminar approaches to epidural steroid injections: a systematic review of comaprative studies for lumbosacral radicular pain. Pain Physician 17: E509-E524.

34. Botwin KP, Natalicchio J, Hanna A (2004) Fluoroscopic guided lumbar interlaminar epidural injections: a prospective evaluation of epidurography contrast patterns and anatomical review of the epidural space. Pain Physician 7: $77-80$.

35. Botwin K, Natalicchio J, Brown LA (2004) Epidurography contrast patterns with fluoroscopic guided lumbar transforaminal epidural injections: a prospective evaluation. Pain Physician 7: 211-215.

36. Friedrich JM, Harrast MA (2010) Lumbar epidural steroid injections: indications, contraindications, risks, and benefits. Curr Sports Med Rep 9 . $43-49$.

37. DePalma MJ, Slipman CW (2008) Evidence-informed management of chronic low back pain with epidural steroid injections. Spine J 8: 45-55

38. Kennedy DJ, Schneider B, Casey E, Rittenberg J, Conrad B, (2013) Vasovagal rates in flouroscopically guided interventional procedures: a study of over 8,000 injections. Pain Med 14: 1854-1859.

39. Benyamin RM, Manchikanti L, Parr AT, Diwan S, Singh V, et al. (2012) The effectiveness of lumbar interlaminar epidural injections in managing chronic low back and lower extremity pain. Pain Physician 15: E363-E404.

40. Harrast MA (2008) Epidural steroid injections for lumbar spinal stenosis. Curr Rev Musculoskelet Med 1: 32-38. 
Citation: Plastaras CT, Kotcharian AS, Chhatre A. Lumbar Epidural Injections: Review of Efficacy and Discussion of Practice Options. J Orthopedics Rheumatol. 2015;2(1): 12.

41. Goodman BS, Posecion LW, Mallempati S, Bayazitoglu M (2008) Complications and pitfalls of lumbar interlaminar and transforaminal epidura injections. Curr Rev Musculoskelet Med 1: 212-222.

42. Smuck M, Fuller BJ, Chiodo A, Benny B, Singaracharlu B, et al. (2008) Accuracy of intermittent fluoroscopy to detect intravascular injection during transforaminal epidural steroid injections. Spine (Phila Pa 1976) 33 : E205-E210.

43. Hong JH, Huh B, Shin $\mathrm{HH}$ (2014) Comparison between digital subtraction angiography and real-time fluoroscopy to detect intravascular injection during lumbar transforaminal epidural injections. Reg Anesth Pain Med 39: 329-332.

44. Novak S, Nemeth WC (2008) The basis for recommending repeating epidural steroid injections for radicular low back pain: a literature review. Arch Phys Med Rehabil 89: 543-552.

45. Gharibo CG, Varlotta GP, Rhame EE, Liu EC, Bendo JA, et al. (2012) Interlaminar versus transforaminal epidural steroids for the treatment of subacute lumbar radicular pain: a randomized, blinded, prospective outcome study. Pain Physician 14: 499-511

46. Lutz GE, Vad VB, Wisneski RJ (1998) Fluoroscopic transforaminal lumbar epidural steroids: an outcome study. Arch Phys Med Rehabil 79: 1362-1366.

47. Riew KD, Yin Y, Gilula L, Bridwell KH, Lenke LG, et al. (2000) The effect of nerve-root injections on the need for operative treatment of lumbar radicular pain. J Bone Joint Surg Am 82-A: 1589-1593.

48. Riew KD, Park JB, Cho YS, Gilula L, Patel A, et al. (2006) Nerve root blocks in the treatment of lumbar radicular pain. J Bone Joint Surg Am 88: 1722-1725.

49. Rados I, Sakic Zdravcevic K, Hrgovic Z (2013) painDETECT questionnaire and lumbar epidural steroid injection for chronic radiculopathy. Eur Neurol 69 27-32.

50. Bartynski WS, Jennings RB, Rothfus WE, Agarwal V (2013) Immediate pain response to interlaminar lumbar epidural steroid administration: response characteristics and effects of anesthetic concentration. AJNR Am J Neuroradiol 34: 239-246.

51. Furman MB, Kothari G, Parikh T, Anderson JG, Khawaja A (2010) Efficacy of fluoroscopically guided, contrast-enhanced lumbosacral interlaminar epidura steroid injections: a pilot study. Pain Med 11: 1328-1334

52. Furman MB, Mehta AR, Kim RE, Simon JI, Patel R, et al. (2010) Injectate volumes needed to reach specific landmarks in lumbar transforaminal epidural injections. PM R 2: 625-635.

53. Manchikanti L, Abdi S, Atluri S, Benyamin RM, Boswell MV, et al. (2013) An update of comprehensive evidence-based guidelines for interventional techniques in chronic spinal pain. Part II: guidance and recommendations. Pain Physician 16: S49-S283.

54. Bogduk N (2004) Lumbar transforaminal injection of corticosteroids, in International Spine Intervention Society. Practice Guidelines for Spinal Diagnostic and Treatment Procedures, p: 187

55. Ahadian FM, McGreevy K, Schulteis G (2011) Lumbar transforaminal epidural dexamethasone: a prospective, randomized, double-blind, dose-response trial. Reg Anesth Pain Med 36: 572-578.

56. Derby R, Lee SH, Date ES, Lee JH, Lee CH (2007) Size and aggregation of corticosteroids used for epidural injections. Pain Med 9: 227-234.

57. El-Yahchouchi C, Geske JR, Carter RE, Diehn FE, Wald JT, et al. (2013) The non inferiority of the nonparticulate steroid dexamethasone vs the particulate steroids betamethasone and triamcinolone in lumbar transforaminal epidura steroid injections. Pain Med 14: 1650-1657.

58. Kim D, Brown J (2011) Efficacy and safety of lumbar epidural dexamethasone versus methylprednisolone in the treatment of lumbar radiculopathy: a comparison of soluble versus particulate steroids. Clin J Pain 27: 518-522.

59. Park $\mathrm{CH}$, Lee $\mathrm{SH}$, Kim BI (2010) Comparison of the effectiveness of lumbar transforaminal epidural injection with particulate and nonparticulate corticosteroids in lumbar radiating pain. Pain Med 11: 1654-1658.

60. Benzon HT, Chew TL, McCarthy RJ, Benzon HA, Walega DR (2012) Comparison of the particle sizes of different steroids and the effect of dilution a review of the relative neurotoxicities of the steroids. Anesthesiology 106 331-338

61. Balderston RA, Albert TJ, Mclntosh T, Wong L, Dolinskas C (1998) Magnetic resonance imaging analysis of lumbar disc changes below scoliosis fusions. A prospective study. Spine (Phila Pa 1976) 23: 54-58

62. Kennedy DJ, Plastaras C, Casey E, Visco CJ, Sigler JD, et al. (2013) Multi-center randomized controlled trial comparing particulate versus nonparticulate corticosteroids via lumbar transforaminal epidural injection for acute unilateral, uni-level radicular pain due to herniated nucleus pulposus. PM R 5: S133.

63. Dreyfuss P, Baker R, Bogduk N (2006) Comparative effectiveness of cervical transforaminal injections with particulate and nonparticulate corticosteroid preparations for cervical radicular pain. Pain Med 7: 237-242.

64. Kennedy DJ, Plastaras C, Casey E, Visco CJ, Rittenberg JD, et al. (2014) Comparative effectiveness of lumbar transforaminal epidural steroid injections with particulate versus nonparticulate corticosteroids for lumbar radicular pain due to intervertebral disc herniation: a prospective, randomized, double-blind trial. Pain Med 15: 548-555.

65. El-Yahchouchi C, Geske JR, Carter RE, Diehn FE, Wald JT, et al. (2014) The noninferiority of nonparticulate steroid dexamethasone vs the particulate steroids betamethasone and triamcinolone in lumbar transforaminal epidural steroid injections. Pain Med 14: 1650-1657.

66. Simon DL, Kunz RD, German JD, Zivkovich V (1989) Allergic or pseudoallergic reaction following epidural steroid deposition and skin testing. Reg Anesth 14 253-255.

67. Burn JM, Langdon L (1974) Duration of action of epidural methyl prednisolone. A study in patients with lumbosciatic syndrome. Am J Phys Med 53: 29-34.

68. Jacobs S, Pullan PT, Potter JM, Shenfield GM (1983) Adrenal suppression following extradural steroids. Anesthesia 38: 953-956.

69. Knight CL, Burnell JC (1980) Systemic side-effects of extradural steroids Anesthesia 35: 593-594.

70. Simon D, Carron H, Rowlingson J (1985) Correspondence. J Bone Joint Surg 67A: 981.

71. Stambough JL, Booth RE Jr, Rothman RH (1984) Transient hypercorticism after epidural steroid injection. A case report. J Bone Joint Surg Am 66: 11151116.

72. Tuel SM, Meythaler JM, Cross LL (1990) Cushing's syndrome from epidural methyprednisolone. Pain 40: 81-84.

73. Smeal WL, Plastaras CT, Garvan C, Eggers MB, Bosse A (2006) Complications of fluoroscopically guided, contrast-enhanced injections of the lumbar spine. Arch Phys Med Rehabil 87: e39.

74. Gonzalez P, Laker SR, Sullivan W, Harwood JE, Akuthota V (2009) The effects of epidural betamethasone on blood glucose in patients with diabetes mellitus. PM R 1: 340-345.

75. Mandel S, Schilling J, Peterson E, Rao DS, Sanders W (2013) A retrospective analysis of vertebral body fractures following epidural steroid injections. J Bone Joint Surg Am 95: 961-964.

76. Houten JK, Errico TJ (2002) Paraplegia after lumbosacral nerve root block: report of three cases. Spine J 2: 70-75

77. Kennedy DJ, Dreyfuss P, Aprill CN, Bogduk N (2009) Paraplegia following image-guided transforaminal lumbar spine epidural steroid injection: two case reports. Pain Med 10: 1389-1394.

78. Tiso RL, Cutler T, Catania JA, Whalen K (2004) Adverse central nervous system sequelae after selective transforaminal block: the role of corticosteroids. Spine J 4: 468-474.

79. Hogan QH, Abram SE (1997) Neural blockade for diagnosis and prognosis. A review. Anesthesiology 86: 216-241

80. Sato C, Sakai A, Ikeda Y, Suzuki H, Sakamoto A (2008) The prolonged analgesic effect of epidural ropivacaine in a rat model of neuropathic pain. 
Citation: Plastaras CT, Kotcharian AS, Chhatre A. Lumbar Epidural Injections: Review of Efficacy and Discussion of Practice Options. J Orthopedics Rheumatol. 2015;2(1): 12.

ISSN: $2334-2846$

Anesth Analg 106: 313-320.

81. Becker DE, Reed KL (2012) Local anesthetics: review of pharmacological considerations. Anesth Prog 59: 90-101.

82. Manchikanti L, Cash KA, McManus CD, Pampati V, Fellows B (2012) Fluoroscopic caudal epidural injections with or without steroids in managing pain of lumbar spinal stenosis: one-year results of randomized, double-blind, active-controlled trial. J Spinal Disord Tech 25: 226-234.

83. Manchikanti L, Singh V, Cash KA, Pampati V, Damron KS, et al. (2012) Effect of fluoroscopically guided caudal epidural steroid or local anesthetic injections in the treatment of lumbar disc herniation and radiculitis: a randomized, controlled, double blind trial with a two-year follow-up. Pain Physician 15 273-286

84. Manchikanti L, Singh V, Cash KA, Pampati V, Falco FJ (2014) A randomized, double-blind, active-control trial of the effectiveness of lumbar interlaminar epidural injections in disc herniation. Pain Physician 17: E61-E74.

85. Manchikanti L, Cash KA, Pampati V, Falco FJ (2014) Transforaminal epidural injections in chronic lumbar disc herniation: a randomized, double-blind active-control trial. Pain Physician 17: E489-E501.

86. Cassuto J, Sinclair R, Bonderovic M (2006) Anti-inflammatory properties of local anesthetics and their present and potential clinical implications. Acta Anaesthesiol Scand 50: 265-282.

87. Bogduk N (2013) Lumbar interlaminar epidural acess, in International Spine Intervention Society. Practice Guidelines for Spinal Diagnostic and Treatment Procedures, p: 516

88. Murthy NS, Maus TP, Behrns CL (2010) Intraforaminal location of the great anterior radiculomedullary artery (artery of Adamkiewicz): a retrospective review. Pain Med 11: 1756-1764.

89. Botwin KP, Gruber RD, Bouchlas CG, Torres-Ramos FM, Freeman TL, et al. (2000) Complications of fluoroscopically guided transforaminal lumbar epidural injections. Arch Phys Med Rehabil 81: 1045-1050.

90. Huston CW, Slipman CW, Garvin C (2005) Complications and side effects of cervical and lumbosacral selective nerve root injections. Arch Phys Med Rehabil 86: 277-283.

91. Stalcup ST, Crall TS, Gilula L, Riew KD (2006) Influence of needle-tip position on the incidence of immediate complications in 2,217 selective lumbar nerve root blocks. Spine J 6: 170-176.

92. Boswell MV, Hansen HC, Trescot AM, Hirsch JA (2003) Epidural steroids in the management of chronic spinal pain and radiculopathy. Pain Physician 6 : 319-334.

93. Abdi S, Datta S, Lucas LF (2005) Role of epidural steroids in the management of chronic spinal pain: a systematic review of effectiveness and complications. Pain Physician 8: 127-143.

94. Abdi S, Datta S, Trescot AM, Schultz DM, Adlaka R, et al. (2007) Epidural steroids in the management of chronic spinal pain: a systematic review. Pain Physician 10: 185-212.

95. Buenaventura RM, Datta S, Abdi S, Smith HS (2009) Systematic review of therapeutic lumbar transforaminal epidural steroid injections. Pain Physician 12: $233-251$

96. Ghahreman A, Ferch R, Bogduk N (2010) The efficacy of transforaminal injection of steroids for the treatment of lumbar radicular pain. Pain Med 11: 1149-1168.

97. Ghahreman A, Bogduk N (2011) Predictors of a favorable response to transforaminal injection of steroids in patients with lumbar radicular pain due to disc herniation. Pain Med 12: 871-879.

98. Wright JG, Swiontkowski MF, Heckman JD (2003) Introducing levels of evidence to the journal. J Bone Joint Surg Am 85-A: 1-3.

99. Rho ME, Tang CT (2011) The efficacy of lumbar epidural steroid injections: transforaminal, interlaminar, and caudal approaches. Phys Med Rehabil Clin N Am 22: 139-148.
100. Manchikanti L, Buenaventura RM, Manchikanti KN, Ruan X, Gupta S, et al. (2012) Effectiveness of therapeutic lumbar transforaminal epidural steroid injections in managing lumbar spinal pain. Pain Physician 15: E199-E245.

101. MacVicar J, King W, Landers MH, Bogduk N (2013) The effectiveness of lumbar transforaminal injection of steroids: a comprehensive review with systematic analysis of the published data. Pain Med 14: 14-28.

102. van Helvoirt H, Apeldoorn AT, Ostelo RW, Knol DL, Arts MP, et al. (2014) Transforaminal epidural steroid injections followed by mechanical diagnosis and tehrapy to prevent surgery for lumbar disc herniation. Pain Med 15 1100-1108.

103. Ploumis A, Christodoulou P, Wood KB, Varvarousis D, Sarni JL, et al. (2014) Caudal vs transforaminal epidural steroid injections as short-term (6 months) pain relief in lumbar spinal stenosis patients with sciatica. Pain Med 15: 379 385 .

104. Bromage PR, Benumof JL (1998) Paraplegia following intracord injection during attempted epidural anesthesia under general anesthesia. Reg Anesth Pain Med 23: 104-107

105. Krane EJ, Dalens BJ, Murat I, Murrell D (1998) The safety of epidurals placed during general anesthesia. Reg Anesth Pain Med 23: 433-438.

106. Saberski LR, Kondamuri S, Osinubi OY (1997) Identification of the epidura space: is loss of resistance to air a safe technique? A review of the complications related to the use of air. Reg Anesth 22: 3-15.

107. Burn JM, Langdon L (1970) Lumbar epidural injection for the treatment of chronic sciatica. Rheumatol Phys Med 10: 368-374.

108. Berman AT, Garbarino JL Jr, Fisher SM, Bosacco SJ (1984) The effects of epidural injection of local anesthetics and corticosteroids on patients with lumbosciatic pain. Clin Orthop Relat Res 188: 144-151.

109.Bogduk N (2013) Lumbar interlaminar epidural acess, in Internationa Spine Intervention Society. Practice Guidelines for Spinal Diagnostic and Treatment Procedures, p: 552.

110. Dilke TF, Burry HC, Grahame R (1973 Extradural corticosteroid injection in management of lumbar nerve root compression. Br Med J 2: 635-637.

111. Chang-Chien GC, Knezevic NN, McCormick Z, Chu SK, Trescot AM, et al. (2014) Transforaminal versus interlaminar approaches to epidural steroid injections: a systematic review of comparative studies for lumbosacra radicular pain. Pain Physician 17: E509-E524.

112. DePalma MJ, Bhargava A, Slipman CW (2005) A critical appraisal of the evidence for selective nerve root injection in the treatment of lumbosacral radiculopathy. Arch Phys Med Rehabil 86: 1477-1483.

113. Gharibo CG, Varlotta GP, Rhame EE, Liu EC, Bendo JA, et al. (2011) Interlaminar versus transforaminal epidural steroids for the treatment of subacute lumbar radicular pain: a randomized, blinded, prospective outcome study. Pain Physician 14: 499-511.

114. Lenoir T, Deloin X, Dauzac C, Rillardon L, Guigui P (2008) Paraplegia after interlaminar epidural steroid injection: a case report. Rev Chir Orthop Reparatrice Appar Mot 94: 697-701.

115. Bogduk N (2013) Lumbar interlaminar epidural acess, in Internationa Spine Intervention Society. Practice Guidelines for Spinal Diagnostic and Treatment Procedures, p: 553.

116. Helliwell M, Robertson JC, Ellia RM (1985) Outpatient treatment of low back pain and sciatica by a single extradural corticosteroid injection. $\mathrm{Br} \mathrm{J}$ Clin Pract 39: 228-231.

117. Manchikanti 1, Cash KA, McManus CD, Pampati V, Benyamin RM (2010) Preliminary results of a randomized, double-blind, controlled trial of fluoroscopic lumbar interlaminar epidural injections in managing chronic lumbar discogenic pain without disc herniation or radiculitis. Pain Physician 13: E279-E292.

118. Manchikanti L, Singh V, Falco FJ, Cash KA, Pampati V (2010) Evaluation of the effectiveness of lumbar interlaminar epidural injections in managing chronic pain of lumbar disc herniation or radiculitis: a randomized, doubleblind, controlled trial. Pain Physician 13: 343-355. 
Citation: Plastaras CT, Kotcharian AS, Chhatre A. Lumbar Epidural Injections: Review of Efficacy and Discussion of Practice Options. J Orthopedics Rheumatol. 2015;2(1): 12.

119. Lee JW, Shin HI, Park SY, Lee GY, Kang HS (2010) Therapeutic trial of fluoroscopic interlaminar epidural steroid injection for axial low back pain: effectiveness and outcome predictors. AJNR Am J Neuroradiol 31: 18171823.

120.Ghai B, Vadaje KS, Wig J, Dhillon MS (2013) Lateral parasagittal versus midline interlaminar lumbar epidural steroid injection for management of low back pain with lumbosacral radicular pain: a double-blind, randomized study. Anesth Analg 117: 219-227.

121. Thomas E, Cyteval C, Abiad L, Picot MC, Taourel P, et al. (2003) Efficacy of transforaminal versus interspinous corticosteroid injection in discal radiculalgia - a prospective randomized, double-blind study. Clin Rheumato 22: 299-304.

122. Ackerman WE 3rd, Ahmad M (2007) The efficacy of lumbar epidural steroid injections in patients with lumbar disc herniations. Anesth Analg 104: 12171222

123. Kolsi I, Delecrin J, Berthelot JM, Thomas L, Prost A, et al. (2000) Efficacy of nerve root versus interspinous injections of glucocorticoids in the treatment of disk-related sciatica. A pilot, prospective, randomized, double-blind study. Joint Bone Spine 67: 113-118.
124. Manchikanti L, Boswell MV, Singh V, Benyamin RM, Fellows B, et al. (2009) Comprehensive evidence-based guidelines for interventional techniques in the management of chronic spinal pain. Pain Physician 12: 699-802.

125. Botwin KP, Gruber RD, Bouchlas CG, Torres-Ramos FM, Hanna A, et al (2001) Complications of fluoroscopically guided caudal epidural injections. Am J Phys Med Rehabil 80: 416-424.

126. Mathews JA, Mills SB, Jenkins VM, Grimes SM, Morkel MJ, et al. (1987) Back pain and sciatica: controlled trials of manipulation, traction, sclerosant and epidural injections. Br J Rheumatol 26: 416-423.

127. Manchikanti L, Cash KA, McManus CD, Pampati V, Smith HS (2011) One-year results of a randomized, double-blind, active controlled trial of fluoroscopic caudal epidural injections with or without steroids in managing chronic discogenic low back pain without disc herniation or radiculitis. 128 Pain Physician 14: 25-36.

128. Iversen T, Solberg TK, Romner B, Wilsgaard T, Twisk J, et al. (2011) Effect of caudal epidural steroid or saline injection in chronic lumbar radiculopathy: multicentre, blinded, randomised controlled trial. BMJ 343: d5278.

129. Parr AT, Manchikanti L, Hameed H, Conn A, Manchikanti KN, et al. (2012) Caudal epidural injections in the management of chronic low back pain: a systematic appraisal of the literature. Pain Physician 15: E159-E198. 